This is the accepted (post-print) version of the following published article:

Kahu, E. R., \& Picton, C. (2020). Using photo elicitation to understand first-year student experiences: Student metaphors of life, university and learning. Active Learning in Higher Education. https://doi.org/10.1177/1469787420908384

\title{
Using photo elicitation to understand first-year student experiences: Student metaphors of life, university, and learning
}

\author{
Kahu, E.R. \& Picton, C.
}

The transition from school to university is challenging and a greater knowledge of the first year student experience will enable staff to better support their students. University and government run student surveys fail to capture the depth and breadth of the firstyear experience and so qualitative research is needed to better to get a more nuanced and holistic understanding of students' lives. The study described in this article used a photo elicitation method. We asked students to choose four images that represented their first year at university. The data - the chosen photographs and the students' explanations of their choices - were thematically analysed, focusing in particular on the diverse metaphors students used to depict three dimensions of their experiences: life, university, and learning. The findings highlight the dual nature of the transition to university - learning to be a university student and learning to be an adult - as well as the challenges and stresses of that process. The lack of agency that students felt is evident. The students likened their journey to a rollercoaster and talked of not being able to keep up with the fast-moving curriculum. They depicted themselves as passive acquirers of knowledge. The findings offer new ways for staff to understand the challenges that potentially disrupt student engagement in the first year. Both students and staff could benefit from recognising the metaphors in their thinking and, potentially, seeking new metaphors that might reveal different and more positive ways of experiencing the first year in higher education. Keywords: student success, student engagement, first-year experience

Key words: First-year experience, photo elicitation, higher education, student engagement 


\section{Introduction}

Starting university is an exciting but challenging time in people's lives. The transition to university is seen as "students' transformation or development, from one life stage to another" (Gale and Parker, 2014: 741) with students who are straight from school often leaving their parental home and shifting to an educational learning context which is substantially different to secondary education. The difficulties associated with this transition lead to many students withdrawing or failing (Edwards and McMillan, 2015). A survey shows a third of first-year Australian students find coping with university challenging, just over half feel no belonging to the university community, and half find managing their study alongside other commitments stressful (Baik et al., 2015). Further evidence of stress comes from a national survey finding that $65 \%$ of young Australian university students report high or very high stress levels (Rickwood et al., 2016). In this context it is unsurprising the firstyear student attrition rate in Australian universities is around 17\% (Australian Government, 2017). These issues are not unique to Australia. For instance, in a UK survey $63 \%$ of university students reported always or often feeling stressed or worried (Neale et al., 2016), although first year attrition there is low, with $8 \%$ of students not continuing to their second year (Higher Education Statistics Authority, 2018). In light of these retention issues and increased concerns about student well-being, a greater understanding of first-year student experiences is needed.

Surveys are the most commonly used tool to measure the student experience with students regularly surveyed by institutions and by government; for example the Student Experience Survey in Australia, the National Survey of Student Engagement in the USA, and the National Student Survey in the UK which surveys students in their final year. However, surveys such as these are limited: they focus on institutional and government interests and lack depth and detail and so do not easily capture the students' full lived experience (Bates et Accepted (postprint) version: Kahu, E. R., \& Picton, C. (2020). Using photo elicitation to understand first-year student experiences: Student metaphors of life, university and learning. Active Learning in Higher Education. 
al., 2019). In-depth qualitative methods, particularly visual research methods, offer a more holistic, student-centric approach. Photo elicitation, using photographs as stimuli in an interview, can "elicit implicit knowledge and self-identities in a way that other methods cannot" (Edgar, 1999: 198) and so may be useful in gaining a more nuanced understanding.

Usage of photo elicitation is increasing due to a number of recognised benefits (Lapenta, 2012). One key benefit is it leads to different, and potentially richer, reflections than straight interviews (Harper, 2002). Harper (2002) suggests this results from visual parts of the brain being "evolutionarily older" (p. 13) and therefore a deeper level of consciousness is evoked. Others (Gillies et al., 2005; Collier, 1957) argue emotions and experiences are more easily expressed in visual form; as Vila (2013) explains "photos speak a language of emotions and meaning" (p. 65). Whatever the reason, photo elicitation data is both qualitatively different and more comprehensive (Samuels, 2004; Mahruf and Shohel, 2012; Collier, 1957). A second strength of photo elicitation is that it can be more empowering. In interviews, the direction of the conversation is predetermined, whereas photo elicitation accords greater agency to participants as they make and explain their image choices (Bates et al., 2019; Lapenta, 2012; Richard and Lahman, 2015). Valuing the student voice is essential: "universities should include a focus on what students have to say in their own words and incorporate such feedback into their priorities" (Grebennikov and Shah, 2013: 606). Photo elicitation offers that possibility. A third benefit of photo elicitation is that it is more engaging and interesting for participants (Frith and Harcourt, 2007; Lapenta, 2012). It helps build trust with the focus on the photographs helping participants feel comfortable and less like studied objects (Mahruf and Shohel, 2012; Banks, 2008).

Debates exist as to which are the best kinds of images for such research. Banks (2008) argues that photographs that are not aligned with the research topic may divert the focus of 
the interview, whereas Harper (2002) found realistic images did not "break the frame" (p. 20) of the participants' normal view and so did not elicit rich reflective data. As well, it is suggested that the researcher choosing the images can constrain participant voices (Richard and Lahman, 2015; Lapenta, 2012). Using more abstract, less specific images mitigates these risks; such photos are polysemic, acting like Rorschach inkblots - open to multiple interpretations (Harper, 2002; Lapenta, 2012; Vila, 2013). As Becker (1986) puts it, "pictures do not simply make assertions... we interact with them in order to arrive at conclusions" (p. 279).

A conceptual metaphor is a way of making an abstract idea or experience more easily understandable by framing it in terms of another more concrete concept (Kövecses, 2017). According to conceptual metaphor theory, our conceptual thinking is fundamentally metaphorical and thus metaphors form an important part of the narratives we use to understand and make sense of the social world (Stephens and Breheny, 2013). As Sfard (1998) puts it, "we live by the metaphors we use" (p. 5). If metaphors do not just reflect reality but shape it, both enabling and constraining behaviours, there is value in understanding the metaphors university students use to depict their experiences. Metaphor analysis can cast new light on familiar processes (Carpenter, 2008).

Metaphors for teaching and learning stem from different learning theories and epistemological orientations (Wegner and Nückles, 2015). Various studies have explored the use of metaphors by lecturers/instructors in higher education (Wegner and Nückles, 2015; Emerson and Mansvelt, 2015; Bager-Elsborg and Greve, 2019). Two overarching metaphors have been identified. The older metaphor, the acquisition metaphor, conceptualises learning as acquiring knowledge, with the human mind characterised as a vessel to be filled with material and the learner as owner of that material (Sfard, 1998). Traditional teaching methods 
such as lectures align with this view, positioning students as passive receivers of knowledge. Despite being the subject of considerable critique, these methods remain due to pressures such as large student cohorts and the 'student as consumer model' (Langer et al., 2018). Molesworth et al. (2009) suggest this market metaphor promotes students seeking to "have a degree rather than be learners" (p. 278) and thus viewing themselves as passive learners. Emerson and Mansvelt (2014) argue that using a different metaphor for education opens up different understandings of student and university roles, responsibilities, and actions.

The more recent metaphor of learning and teaching, the participation metaphor, is more active: 'having' is replaced by 'doing' and learning is about being a member of a community (Sfard, 1998). Metaphors highlight some aspects of experience while obscuring others (Creed and McIlveen, 2018) and Sfard (1998) argues educational research is "caught between" (p. 5) the acquisition and participation metaphors and that we need both as each has advantages and offers something the other cannot. Findings from Päuler-Kuppinger and Jucks (2017) suggest that as students progress through university, their conceptions of teaching develop from a lecturer/content centred orientation (aligning with the acquisition metaphor) to a more student/learning centred orientation.

A few studies have explored higher education students' use of metaphor. For instance, Bozlk (2002) asked students to create metaphors of themselves as learners; drawing on the acquisition metaphor, the students primarily saw themselves as passive consumers of information using metaphors such as a sponge. Lecturers/instructors were depicted as the ones feeding them information. Other studies explored students' use of images or metaphor in talking about their wider university experience. For instance, Luzeckyj et al. (2017) asked first in family students to use metaphors to describe their experience. The findings identified three types of metaphors: metaphors related to a journey, metaphors illustrating unknowns, 
and metaphors about not belonging. Specific metaphors included the ocean, a rollercoaster, and a fish out of water.

Life as a journey is a commonly used metaphor: purposes are destinations, actions are steps along the way, and success is getting somewhere (Kövecses and Benczes, 2010). Universities themselves use the journey metaphor in student facing communications; for instance, the first week for new students is 'orientation' and degree choices are 'pathways'. Often, the journey metaphor is explicit; for example: "Your student journey...Your background, interests and ambitions will all influence the path you choose" (University of Tasmania, 2019). Landau et al. (2014) demonstrated the positive benefits of priming students with a journey metaphor: increased confidence, improved study habits, and better examination performance. They contrasted an active journey metaphor (images and text of walking along a path towards a goal) with a passive journey metaphor (images and text of riding a train towards a goal). Students primed with the active metaphor reported higher levels of confidence and a greater sense of connection between their current identity and their potential academic identity. However, Langer et al. (2018) argue that the student journey metaphor is problematic because it implies acquiring a degree is a straightforward process where students start as empty vessels and follow a straight pathway while being passively filled with knowledge.

Research with diverse cohorts of students has found students use a rollercoaster metaphor to illustrate the highs and lows of their first year (Wiesenberg, 2001; Kahu et al., 2015; Luzeckyj et al., 2017; Morrison-Saunders et al., 2010). The lows of the rollercoaster reflect the stress students experience, caused by a range of factors such as academic demands, procrastination, and finances (Stallman and Hurst, 2016). Another critical cause of stress is study/life balance; lifeload is an important influence on student engagement and wellbeing 
(Kahu, 2013). In particular, students with greater paid work have more stress and lower grades (Callender, 2008; Stallman, 2010). Lifeload issues tend to be compounded for students from lower socioeconomic backgrounds (Devlin and McKay, 2017).

This literature highlights the need for a more nuanced understanding of the university journey from the student perspective with further studies needed to look more closely into how students use metaphor to explain, and understand, their experiences - particularly in their first year. This study aims to address this gap. The research questions driving the study are: What aspects of experiences do first year students focus on and what metaphors do they use?

\section{Method}

The interviews reported on are from a project following 19 students through their first year (in 2016) at an Australian regional university. All the participants were 17 years of age at the start, full-time direct entry students from high school, studying a range of disciplines including arts, health, and business. All were Australians with European ancestry and 11 were first in their family to attend university. Following hour long interviews before starting university, the students attended weekly 15-20 minute long semi-structured interviews throughout their first two semesters. In the interviews, the students could talk about any aspects of their week, and at times were asked specific questions to keep the conversation flowing or to direct their attention to topics they may not have considered. All interviews were audio recorded and fully transcribed. Ethical approval for the study was obtained from the Human Research Ethics Committee of the University of the Sunshine Coast.

Midway through the second semester, instead of the usual interview, the students were asked to choose four colour photographs that represented their first-year experiences from a set of 40. Fourteen students (eight female and six male) took part; of the others, one 
had withdrawn from university, one had withdrawn from the research, and three were not available that week. To encourage metaphorical thinking, we used decontextualized photographs of a wide range of scenes, objects, and people rather than images of students and universities. The set of photographs is designed as a conversation-building tool in therapeutic and educational contexts (Innovative Resources, 2007). In the interview, the students explained their choices with the interviewer prompting for more detail and information as needed. This exercise aimed to encourage the students to reflect on their experiences in a more holistic way, rather than focusing on the daily and weekly routines of university life. As well, choosing multiple images enabled students to talk about different dimensions of their experiences. Interviews were transcribed in full with identifying details removed and pseudonyms used to protect participant anonymity.

There is no single way to do a metaphorical analysis; approaches range from detailed identification of metaphorical linguistic expressions (Steger, 2007; Todd and Harrison, 2008) to organising data into metaphorical themes (Carpenter, 2008). The analysis in this study sits in between: The data - the photos chosen and the transcribed interviews - were thematically analysed (Braun and Clarke, 2013) paying particular attention to both the linguistic and conceptual metaphors students used to make sense of and explain elements of their experiences. As the same metaphor or image could represent different aspects of experience for different students, quotes were coded both for their metaphor (e.g. fire) and the object of that metaphor (e.g. stress). While some metaphors came directly from the photographs, others emerged in the students' explanations. There is also no single answer as to what counts as a metaphor in text; rather it is a matter for the researcher's judgement (Todd and Harrison, 2008) and so a useful analysis strategy is to present and discuss findings with critical colleagues (Steger, 2007). In this study, the first author conducted the initial analysis and then 
shared it with the second author. Following discussions, the analysis was restructured to focus on the three dimensions of experience described by the metaphors rather than focussing on the metaphors themselves.

\section{Findings}

The findings present students' depictions of three dimensions of their experiences: life, university, and learning. Together these illustrate the complexity of the first-year experience and the challenges students face. Figure one shows the most often chosen images; however, different students sometimes chose the same image to represent different ideas.

Insert Figure 1 here

\section{Life}

The students chose a range of images representing this as a new phase of life - some literal (e.g. cutlery) and some metaphorical (e.g. a box of pastels). The students differentiated between their past identities as high school students and this new life as an adult: "My high school life, it feels like a past life now...I'm not the little kid I was anymore” (Matthew). Isaac highlighted that a grown-up life has to be taken more seriously: "Just forcing yourself to sort of grow up and like you can't really mess around anymore, this is life sort of thing. Like this is important and you've got to do it". Later, Isaac described university as "where you can really find yourself as a person”. Melanie also talked about university as an “opportunity to find yourself” and described herself as a wiser and more understanding person because of her university experiences. 
A key benefit of this new adult life was the perceived freedom from the constraints of high school: "Instead of having that really strict schedule in high school...they're always on your back about assignments or giving you activities and stuff" (Karla); and freedom from the constraints of parents: "I don't have to tell my mother where I'm going, every day. What I'm doing, every day" (Peter). Melanie sums up these differences: "the opportunity to just do things myself and think for myself and plan for myself, and not be babied... when you're in high school, when you're still developing as a teenager, you get told what to do all the time".

Freedom came at a cost however, particularly for students who moved out of home. Learning to be independent was challenging as Tony highlighted: "the sheer volume of adjustments that have been done over the last, not even 12 months, eight months since moving out of home". The students missed the comforts of home and struggled to manage their multiple roles as Karla explains:

It really sucks... having to sort of take care of yourself... Like, you know, I have friends who are still at home and their parents are still making their dinner. They're doing their washing and just cleaning up the place and I just think oh my god, that's such luxury, because you just have to focus on your learning... because it's all really new to me, it sort of gets in the way and I sort of focus more on, you know, like having to work so I can live out of home, instead of uni[versity].

Karla uses a conceptual metaphor where life roles are objects that can "get in the way" of other roles. This metaphor was evident throughout the students' talk - different roles or tasks had to be "juggled" or "squished" into the container of time: "Just juggling everything and you're kind of squishing everything into a week, or like a month...Work, friends, family, uni, just life and trying to relax at some stage" (Mia). Alison's explanation of her choice of photograph, a car wreck, illustrates that tasks do not always fit into the available 
space and that students have little control: "Everything's hit you real fast, real hard. You're still exhausted from last semester and you still have to try and mesh life in with it as well, and it's just a big mess".

The benefits and challenges of adult life were represented by some students as a rollercoaster. While Peter liked university, he missed his family:

You could say it's been a rollercoaster. It's had its ups and downs, dibs and dabs. The ups of knowing that I'm getting my career but then it's the downs of not having a home cooked meal each night... I attempted to make something that Mum made the other day. It just tasted [awful]. I was like, 'Mum what ingredient didn't you tell me?' She said, 'No I told you about everything' I think it was like a motherly love was one of the secret things.

Peter's description of motherly love as the missing ingredient suggests it is not just the practical convenience of home cooked meals that he was missing. While Peter continued to be homesick, Matthew grew into his independence: "I don't live with Mum, I don't have my safety net now sort of thing. When I started it was hard. But now that I've been on the rollercoaster for a while, it's normal, and I don't want my safety net back".

For some students, a positive aspect of their new life was the opportunity to meet and interact with a diverse range of people. Five students chose images depicting multiculturalism; while most were literal images such as a Chinese dragon, Melanie chose a box of pastels:

The colours, they kind of represented multiculturalism...In high school you really don't get to meet all the types of people, all types of colours ...so my colours have been kind of constricted, and now they're becoming, it's like an open pencil case, like an open pastel thing. 
Melanie uses a photography metaphor which likens experience to vision - vision that has been "constricted" before but which is now "open". Similarly, she talked about "letting go of your old perspectives and lenses, or understanding of the world". The opportunity to meet people from diverse backgrounds, in class and in accommodation, was an unexpected means of learning. Students such as Isaac contrasted this with his narrow high school experiences: "Coming from a place where there's nothing but Australians and you can be like it's very different and I'm really enjoying learning about it and like hearing about their countries and stuff”'

\section{University}

The students also chose images that represented their university experiences more specifically. The most common conceptual metaphor was university as a journey, represented by diverse images including a rollercoaster, someone on a bike, and someone climbing a mountain. Heidi summarises the journey metaphor beautifully:

I guess uni, for me, is a journey...turns and twists, and, like, the different weather. Like, it's snowing for example... you go through those times of hard and stuff like that, but I can see it's kind of going up a hill, so you would get to a point where you can see a view, and it's like those moments that you kind of stop and you're like - you know, you haven't necessarily made it in a sense but you made a big dent and you're on the way. And there's points in there that you get across the journey that you're like - moments of achievement. It's like handing in assignments.

The challenges, which are outside of her control, are depicted as twists and turns in the path and inclement weather. The hill portrays the journey as difficult but with a 
worthwhile destination - the top of the hill with a view. She also draws in the idea that the journey has stages, with interim rewards along the way.

The rollercoaster, as well as depicting life as an adult, was the most commonly chosen image to represent the nature of the first-year journey and its rewards and stresses. The "ups" of the university rollercoaster included submitting assignments, grades, and social events, while the "downs" were doing assignments, stress, and workload. Sienna describes the experience:

The rollercoaster ride... there's going to ups and downs throughout uni.

So the stress is kind of the down but then you've got the exciting parts

like the social parts... And another up is when you get your results and they're great. Like that's - that's so exciting.

The rollercoaster was one of extreme emotions - excitement and fun alternating with fear and stress. The fear was strong at the start and contrasted with prior expectations; for example, Zara expected university to be fun but found it "terrifying":

I guess my journey, my railway tracks and a bit of rollercoasters too. I had this expectation that it was going to be so fun and I was going to love it and it suddenly got really terrifying and didn't feel right.

For some students the journey was getting easier and less like a rollercoaster: "Once the first initial dip is over, then it's not too bad, and it's enjoyable" (Felix). Students often depicted a stark contrast between their first and second semesters: "Last semester, I just felt lost, nothing really felt right, where now I just feel relaxed" (Zara).

Rather than a single image or metaphor, some students chose a pair of contrasting images to represent the fluctuations. For example, Isaac chose a burning house, saying: "things become very stressful and that sort of quitting feeling because everything has built experiences: Student metaphors of life, university and learning. Active Learning in Higher Education. 
up, you don't know if you're able to handle it all". He also selected a cyclist silhouetted against a sunset, describing his experience as: "enjoyable, peaceful, extremely satisfying”.

Stress was a key theme. For instance Sienna also selected the burning house:

“Sometimes I feel like this. Like everything's just on fire, is burning, it's crazy with all the stress". The chosen images and the students' explanations suggest that the stress is extreme and out of their control. Linking back to the ups and downs of the rollercoaster, stress was depicted as transient and cyclical: "I picked the car wreck, just because sometimes at uni you feel like everything's a bit of a wreck. But after the accident's all cleared away it's like nothing ever happened" (Alison).

Two students mentioned the importance of company and support during the journey: "I think it makes the journey easier, doing it with other people" (Heidi). Karla chose an image of a person abseiling, capturing in one metaphor the challenges, the goal, and the importance of support: "You're sort of climbing to get to your degree [laughs]. There's a goal in mind and there's a bit of a struggle but the ropes and that, you've got support".

As well as illustrating the fluctuations of the first year, the journey metaphor was used to depict their goals, the journey's destination: the degree, a "better" job, or a particular career identity. For five students the degree itself was the goal. For example, Elisabeth visualised her graduation as a motivation technique; she frames the qualification as a possession, something she will "have", drawing on the acquisition metaphor of learning as discussed:

When I get into trouble and I have difficulties, I just sort of imagine myself getting up on that stage in the end and getting my little certificate... How good would that be? You'll have a uni degree. That's such a good thing to have, such a life accomplishment. 
Isaac was also motivated by and found enjoyment in his sense of purpose. Talking about his future, he describes himself as "working towards it", depicting control over the process.

\footnotetext{
Knowing this is what I really want to do in life and I'm working towards it. So for me it's a really good feeling because it's something I feel like I sort of - in high school I didn't know what I was really working towards so it's a very different change and I really enjoy it.
}

While Isaac saw university as very different to school, in part because of his clear goal, other students saw university as purely a means to an end. Alison for example used a "stepping stone" metaphor: "It's something you have to do to be a lawyer or to go in to child protection... so it's like a stepping stone to where I want to be in the real world, I have to do this. Kind of like school". Alison's description of "I have to do this" and her positioning of university as not in the "real world" conveys reluctant compulsion rather than enjoyment. Luke, who was struggling with his study after failing his first semester, was similar. He chose an image of a young man in a mirror putting on a tie to represent his goal: to get a good job. His lack of enjoyment in the process is evident:

I just want the end result. I just want the degree so I can then get a good cushy job where I won't have to do much and get paid money. The actual experience of going to uni I'm not that attached to, that's just a means, an end to the means.

The student journey was not always seen as a single pathway to a clear destination. Some students were confident that their initial goal was still the right destination. For example, Sienna chose an image of a sunset to depict her goal: "it's definitely the best degree 
possible for me. I can't see myself doing anything else". For other students, the journey metaphor represented new potential destinations: "you go on along one path, there might be a branch of where you could go either way" (Alison).

\section{Learning}

The third theme in the students' talk was their learning. Only one student, Tony, chose images specifically related to course content. As well as an image of cracked mud, representing "dry content", Tony selected an image of shredded paper:

I chose this one because it's a whole lot of notes. A lot of interconnectedness from a lot of different subjects. Again seems disjointed but it is, in fact, connected. Also the sheer volume of new content.

The conceptual metaphor of learning represented here and in other students' talk is of knowledge as stuff: it has "volume", can be "dry", and is "disjointed" or "connected". Students talked about course content being "given to", "thrown", or, in an extreme case, "dumped" on students. The goal, according to Mia, was to get "more on top of things". For some students, such as Isaac, this was a rewarding experience: "Learning about stuff, like you've chosen to learn about and want to pursue". For others, like Alison, the quantity and the newness of the content was daunting: "It's always different stuff and it's always a new assignment, it's always a new topic”.

An extension of this metaphor was learning as storage where the "stuff" must be successfully stored in their heads: "I'll never get it" (Elisabeth) and "I take in a lot of information" (Alison). More physical metaphors of concrete and a sponge were also used: "we didn't really have time to cement that in your head" (Karla) and "you've got no actual time to work and absorb what we're doing" (Tony). Here, the student, depicted as a passive recipient, has insufficient time to acquire the knowledge. The students talked about being 
"behind" and having to "catch up", depicting the curriculum as moving (rapidly) away from them. For example, Elisabeth chose an image of a clock, saying she wished she could "freeze time for a week and catch up". She went on to say: "that scares me, not being able to understand something, and then that fear of if I'm not going to get it now, then I'll never get it". Students' stress from this lack of time is evident: "That's exactly how my head felt. Just on fire. Like there's just too much to do and not enough time and just up in flames" (Sienna). A lack of control was also an issue. For example, Karla chose an image of someone swimming: "the water just carries you away...like the weeks go on and you just have to go with it. Like, they're giving up all new content and you just take it”. Karla's imagery is of staff controlling the movement of the curriculum, while students have no control and so have to "go with it" and "take it".

An important characteristic of the "stuff" was its perceived relevance. When the content aligned with the students' interests and goals, the process of acquiring knowledge was easier: it was more likely to "stay in my head" (Sienna) or "stick in my mind" (Heidi). For some, theoretical content was not seen as relevant to the job they would do; it did not "line up" or "fit with the real world" (Tony). This impacted their motivation to learn: "I find being out in the real world a lot better. Real world stuff, instead of writing about policing, which I'm not really interested in" (Alison).

\section{Discussion and conclusion}

In using a metaphorical approach, these findings shed new light on a well-researched topic highlighting that the transition to university is twofold: students are simultaneously adapting to being a university student and to being an adult. It is unsurprising that students in this study, as in other research (e.g. Luzeckyj et al., 2017; Paulson and Armstrong, 2011) depict university as a journey. That it is more complex is highlighted by the findings. The 
tumultuous nature of the journey is evidenced by the rollercoaster metaphor describing the practical, emotional, and psychological highs and lows of the first year - as university students and as independent adults. Part of the rollercoaster ride is stress, depicted in the study by burning buildings and car wrecks. As found in Pitt et al.'s (2018) study, assessments were the commonest stressors. Another critical cause of stress for the students was juggling life roles: study, relationships, paid work, and leisure activities. An important finding in the study is the students' perceived lack of control of parts of their university journey: the stress, lifeload, and their learning.

The importance of coming to university to get a degree versus to learn was evident in how the students depicted their learning. The destination of the journey was the most important thing for some students such as Luke whose motivation for attending university was to get a degree to get a good job. While we are not suggesting this is a single causal factor, he was not enjoying university and was failing his courses, in stark contrast with Isaac who came to university because he enjoyed learning as well as to reach his goal.

Almost without exception, the students used a knowledge as stuff metaphor to describe their learning, paralleling Bozlk's (2002) study where students used a sponge metaphor. In the study described in this article, time pressures alongside the sheer quantity of new material, contributed to students viewing themselves as passive recipients in the learning process, thus supporting studies telling us that the knowledge acquisition metaphor is still the most dominant. This is unsurprising given that first year courses are often building a foundation of background material that students need for future years. According to conceptual metaphor theory, metaphors do not just reveal and hide different aspects of experience, they also influence how we act (Kövecses, 2017). Knowledge as stuff encourages shallow rote learning rather than more active, critical, and deep learning. Given the 
distinction made between a behavioural perspective of knowledge acquisition, which positions students as passive recipients, and a cognitive perspective, which positions students as active in creating the knowledge (Martínez et al., 2001), there is scope for lecturers/instructors to more explicitly draw on the latter and thus encourage students to take greater control of their learning at university. Knowledge is still stuff, but the student has a role in fabricating and critiquing the stuff.

Photo elicitation proved a valuable method for triggering metaphorical thinking which, in comparison to the other weekly interviews, enabled the students to step back from daily life and talk more holistically about their experiences. While a different set of photos may have elicited different data, the students chose a wide range and the analysis reveals a shared and relatively narrow set of metaphorical understandings. However, it is important to acknowledge the limitations of this approach. Metaphorical thinking does not come easily to everyone and a couple of students disliked the task: "I hate doing the metaphorical stuff" (Felix) and "I'm not too great at this sort of thing" (Tony). A second issue was that the interviewer had an established relationship with the students. While this meant the students were comfortable and so potentially disclosed more, one student took the task less seriously, perhaps because he was so comfortable. This may have been less likely without that prior relationship. This sample is from a single Australian regional university with students who had already survived their first semester. There would be value in using this method with other student cohorts - earlier in the first year, at other institutions, or other levels of study. In particular, future work is needed with students in different countries or with different cultural backgrounds, as they may select different metaphors.

In conclusion, while the student journey metaphor as commonly used by institutions has value, a more realistic and beneficial depiction would emphasise the student's agency in experiences: Student metaphors of life, university and learning. Active Learning in Higher Education. 
the process and highlight that the journey may not be straightforward. At university, as with all good trips, it is not just the final destination that matters, but the journey itself. This approach may better prepare students for their year. In addition, as Carpenter (2008) highlights, metaphors can be useful for staff (whether lecturers, personal tutors, support staff, or student counsellors) to identify valuable interventions. The process used here, where a student selects images that capture their experience, could be used to gain insight into a student's perceptions. Alternative metaphors could then be suggested that might, for example, offer the student a greater sense of agency or purpose. For example, a hilly bike ride may be a more useful metaphor for their wider experience than a rollercoaster as it positions the student as having some control over the process and emphasises both the journey and the destination. Equally, depicting learning as students building their own construction from the materials provided is a more agentic metaphor than students simply storing the "stuff" that staff give them.

\section{References}

Australian Government (2017) Attrition, Success and Retention. Available at: https://docs.education.gov.au/documents/2017-section-15-attrition-success-and-retention.

Bager-Elsborg A and Greve L (2019) Establishing a method for analysing metaphors in higher education teaching: A case from business management teaching. Higher Education Research \& Development 38(7): 1329-1342.

Baik C, Naylor R and Arkoudis S (2015) First Year Experience in Australian Universities: Findings from Two Decades, 1994-2014. Melbourne, Australia: Melbourne Centre for the Study of Higher Education.

Banks M (2008) Using Visual Data in Qualitative Research, London, United Kingdom: Sage.

Bates EA, Kaye LK and McCann JJ (2019) A snapshot of the student experience: Exploring student satisfaction through the use of photographic elicitation. Journal of Further and Higher Education 43(3): 291-304.

Becker HS (1986) Doing Things Together, Evanston, IL: Northwestern University Press. 
Bozlk M (2002) The college student as learner: Insight gained through metaphor analysis. College Student Journal 36(1): 142-151.

Braun V and Clarke V (2013) Successful Qualitative Research: A Practical Guide for Beginners, London, United Kingdom: Sage.

Callender C (2008) The impact of term-time employment on higher education students' academic attainment and achievement. Journal of Education Policy 23(4): 359-377.

Carpenter J (2008) Metaphors in qualitative research: Shedding light or casting shadows? Research in Nursing \& Health 31(3): 274-282.

Collier J (1957) Photography in anthropology: A report on two experiments. American Anthropologist 59(5): 843-859.

Creed A and McIlveen P (2018) Metaphor identification as a research method for the study of career. International Journal for Educational and Vocational Guidance 18(1): 27-44.

Devlin M and McKay J (2017) Facilitating Success for Students from Low Socioeconomic Status Backgrounds at Regional Universities. Ballarat, Australia: Federation University, 2022.

Edgar I (1999) The imagework method in health and social science research. Qualitative Health Research 9(2): 198-211.

Edwards D and McMillan J (2015) Completing University in a Growing Sector: Is Equity an Issue? Australian Council for Educational Research.

Emerson L and Mansvelt J (2014) 'If they're the customer, I'm the meat in the sandwich': An exploration of tertiary teachers' metaphorical constructions of teaching. Higher Education Research \& Development 33(3): 469-482.

Emerson L and Mansvelt J (2015) Buckets and fire: Metaphors in tertiary teaching. Studies in Higher Education 40(10): 1872-1888.

Frith H and Harcourt D (2007) Using photographs to capture women's experiences of chemotherapy: Reflecting on the method. Qualitative Health Research 17(10): 1340-1350.

Gale T and Parker S (2014) Navigating change: A typology of student transition in higher education. Studies in Higher Education 39(5): 734-753.

Gillies V, Harden A, Johnson K, et al. (2005) Painting pictures of embodied experience: The use of nonverbal data production for the study of embodiment. Qualitative Research in Psychology 2(3): 199-212.

Grebennikov L and Shah M (2013) Student voice: Using qualitative feedback from students to enhance their university experience. Teaching in Higher Education 18(6): 606-618.

Harper D (2002) Talking about pictures: A case for photo elicitation. Visual Studies 17(1): 1326.

Accepted (postprint) version: Kahu, E. R., \& Picton, C. (2020). Using photo elicitation to understand first-year student experiences: Student metaphors of life, university and learning. Active Learning in Higher Education.

https://doi.org/10.1177/1469787420908384 
Higher Education Statistics Authority (2018) Non-continuation: UK Performance Indicators 2017/18. Available at https://www.hesa.ac.uk/news/07-03-2019/non-continuation-tables\#noncontinuation

Innovative Resources (2007) Picture This: 75 Colour Photographs for Conversation and Reflection, Kangaroo Flat, Australia: Innovative Resources.

Kahu ER (2013) Framing student engagement in higher education. Studies in Higher Education 38(5): 758-773.

Kahu ER, Stephens CV, Leach L, et al. (2015) Linking academic emotions and student engagement: Mature-aged distance students' transition to university. Journal of Further and Higher Education 39(4): 481-497.

Kövecses Z (2017) Conceptual metaphor theory. In: Semino E and Demjén Z (eds) The Routledge Handbook of Metaphor and Language. London, United Kingdom: Routledge, 1327.

Kövecses Z and Benczes R (2010) Metaphor: A Practical Introduction, Oxford, United Kingdom: Oxford University Press.

Landau MJ, Oyserman D, Keefer LA, et al. (2014) The college journey and academic engagement: How metaphor use enhances identity-based motivation. Journal of Personality and Social Psychology 106(5): 679-698.

Langer S, Bunn G and Fellows N (2018) Towards a psychosocial pedagogy: The 'student journey', intersubjectivity, and the development of agency. Learning and Teaching in Action 13(1):1-18.

Lapenta F (2012) Some theoretical and methodological views on photo-elicitation. In: Margolis E and Pauwels L (eds) The Sage Handbook of Visual Research Methods. London, United Kingdom: Sage, 201-213.

Luzeckyj A, McCann B, Graham C, et al. (2017) Being first in family: Motivations and metaphors. Higher Education Research and Development 36(6): 1237-1250.

Mahruf M and Shohel C (2012) Nostalgia, transition and the school: An innovative approach of using photographic images as a visual method in educational research. International Journal of Research \& Method in Education 35(3): 269-292.

Martínez MA, Sauleda N and Huber GL (2001) Metaphors as blueprints of thinking about teaching and learning. Teaching and Teacher Education 17(8): 965-977.

Molesworth M, Nixon E and Scullion R (2009) Having, being and higher education: The marketisation of the university and the transformation of the student into consumer. Teaching in Higher Education 14(3): 277-287.

Morrison-Saunders A, Moore S, Hughes M, et al. (2010) Coming to terms with research practice: Riding the emotional rollercoaster of doctoral research studies. In: Thomson $\mathrm{P}$ and Walker M (eds) The Routledge Doctoral Supervisor's Companion: Supporting Effective 
Research in Education and the Social Sciences. London, United Kingdom: Routledge, 206218.

Neale I, Piggott L, Hansom J, et al. (2016) Student Resilience: Unite Students Insight Report. Bristol, United Kingdom: Unite Students.

Päuler-Kuppinger L and Jucks R (2017) Perspectives on teaching: Conceptions of teaching and epistemological beliefs of university academics and students in different domains. Active Learning in Higher Education 18(1): 63-76.

Paulson EJ and Armstrong SL (2011) Mountains and pit bulls: Students' metaphors for college transitional reading and writing. Journal of Adolescent \& Adult Literacy 54(7): 494-503.

Pitt A, Oprescu F, Tapia G, et al. (2018) An exploratory study of students' weekly stress levels and sources of stress during the semester. Active Learning in Higher Education 19(1): 61-75.

Richard VM and Lahman MK (2015) Photo-elicitation: Reflexivity on method, analysis, and graphic portraits. International Journal of Research \& Method in Education 38(1): 3-22.

Rickwood D, O’Sullivan S, Crisp D, et al. (2016) National Tertiary Student Wellbeing Survey 2016. Canberra, Australia: Headspace.

Samuels J (2004) Breaking the ethnographer's frames: Reflections on the use of photo elicitation in understanding Sri Lankan monastic culture. American Behavioral Scientist 47(12): 1528-1550.

Sfard A (1998) On two metaphors for learning and the dangers of choosing just one. Educational Researcher 27(2): 4-13.

Stallman HM (2010) Psychological distress in university students: A comparison with general population data. Australian Psychologist 45(4): 249-257.

Stallman HM and Hurst CP (2016) The University Stress Scale: Measuring domains and extent of stress in university students. Australian Psychologist 51(2): 128-134.

Steger T (2007) The stories metaphors tell: Metaphors as a tool to decipher tacit aspects in narratives. Field Methods 19(1): 3-23.

Stephens C and Breheny M (2013) Narrative analysis in psychological research: An integrated approach to interpreting stories. Qualitative Research in Psychology 10(1): 14-27.

Todd Z and Harrison SJ (2008) Metaphor analysis. In: Hesse-Biber SN and Leavy P (eds) Handbook of Emergent Methods. New York, NY: The Guilford Press, 479-494.

University of Tasmania. (2019) Your Student Journey. Available at: https://www.utas.edu.au/riawunna/your-journey.

Vila P (2013) The importance of photo-interviewing as a research method in the study of identity construction processes: An illustration from the US-Mexico Border. Visual Anthropology 26(1): 51-68. 
Wegner E and Nückles M (2015) Knowledge acquisition or participation in communities of practice? Academics' metaphors of teaching and learning at the university. Studies in Higher Education 40(4): 624-643.

Wiesenberg F (2001) The roller coaster life of the online learner: How distance educators can help students cope. Canadian Journal of University Continuing Education 27(2): 33-60. 
Accepted (postprint) version: Kahu, E. R., \& Picton, C. (2020). Using photo elicitation to understand first-year student experiences: Student metaphors of life, university and learning. Active Learning in Higher Education.

https://doi.org/10.1177/1469787420908384 
Using photo elicitation to understand

first-year student experiences: Student

metaphors of life, university and learning

Kahu, ER

2022-03

22/04/2023 - Downloaded from MASSEY RESEARCH ONLINE 